\title{
WORLD
}

RESOURCES

WORKING PAPER

\author{
I N S T I T UT E
}

\section{MAINSTREAMING CLIMATE CHANGE ADAPTATION IN KENYA: LESSONS FROM MAKUENI AND WAJIR COUNTIES}

\section{EXECUTIVE SUMMARY}

Mainstreaming adaptation-which entails integrating climate risks and actions into development planning across sectors and from the national to the local level-is essential for making development more resilient to climate change. However, it is challenging for many reasons, including a lack of information on climate risks and limited capacity to integrate climate information into development planning.

- This paper examines the process of mainstreaming climate risks into county-level development plans in Kenya through two case studies. It highlights the enabling factors and challenges that two counties-Makueni and Wajir-have encountered in mainstreaming climate risks based on interviews with Kenya's Council of Governors and county governments and an analysis of county plans.

- Comparisons between counties show that Makueni and Wajir have made strong progress on mainstreaming climate change adaptation by establishing County Climate Change Funds, which have enabled adaptation planners to incorporate climate information and prioritize adaptation measures in their County Integrated Development Plans.

- The experiences of Makueni and Wajir Counties illustrate the challenges of integrating adaptation into planning, which can be addressed by expanding learning and strengthening institutional memory among county- and ward-level planners on how to apply climate information to planning processes, improve fund management, and enhance guidance on selecting and implementing appropriate adaptation measures.

\section{CONTENTS}

1. Introduction 3

2. Purpose and Scope of the Paper ................. 4

3. Methodology..................................... 5

4. Mainstreaming Adaptation at the National Level ....7

5. County Climate Change Funds and Climate Information Services Plans ............................ 8

6. Analysis of County Integrated Development Plans 10

7. Lessons Learned from Makueni County ........... 12

8. Lessons Learned from Wajir County ................ 15

9. Findings ............................................ 17

10. Recommendations and Conclusion .............. 18

Appendix A: Factors That Enable Implementation of Mainstreamed Adaptation .............................20

Appendix B: Interview Questionnaire ................20

Appendix C: Piloting CCCF Mechanisms ............... 21

References .........................................22

Working Papers contain preliminary research, analysis, findings, and recommendations. They are circulated to stimulate timely discussion and critical feedback, and to influence ongoing debate on emerging issues. Working papers may eventually be published in another form and their content may be revised.

Suggested Citation: Chaudhury, M., T. Summerlin, and N. Ginoya. 2020. "Mainstreaming Climate Change Adaptation in Kenya: Lessons from Makueni and Wajir Counties." Working Paper. Washington, DC: World Resources Institute. Available online at www.wri.org/publication/mainstreaming-adaptationkenya. 


\section{Background}

Kenya is highly vulnerable to climate change, and intensifying climate change impacts pose mounting challenges to the progress the country has made toward achieving its development goals. National and local governments in Kenya have recognized that mainstreaming adaptation into development plans and policies across sectors is essential for better management of the increasing risks from climate change and for building resilience-as have governments around the world. Mainstreaming adaptation into development plans and policies can improve the

\section{Key Findings from the Working Paper}

口

Establishing County Climate Change Funds (CCCFs) is critical for mainstreaming climate adaptation into County Integrated Development Plans (CIDPs) in Kenya. CCCFs provide financial support to counties to propose, prioritize, and implement necessary adaptation actions. They enable county adaptation planners to receive training on how to integrate information on climate risks, hazards, and vulnerabilities into the plans, and how to align with national climate change policies while delivering on local adaptation priorities.

- County-level mainstreaming requires strong leadership. Makueni County's passionate governor and Wajir County's "opinion leaders," including teachers and agriculture officers, champion mainstreaming by sharing information about climate change and advocating that communities prioritize adaptation.

- Robust stakeholder engagement is essential for capturing diverse views within the counties. Widespread engagement, from national-level experts to members of small communities and nomadic pastoralists, is a key component of Kenya's success in mainstreaming adaptation into CIDPs, and is worthwhile despite the time, funding, and coordination required.

Adaptation action appears to be leading to resilient development benefits. Recently implemented adaptation projects in Makueni and Wajir Counties are showing early signs of benefits such as improving water access and conservation and reducing women's burden of fetching water, improving the livelihoods of thousands of people.

- Kenya's Council of Governors (CoG) can use these findings to better design the mainstreaming process in counties beyond Makueni and Wajir that have also established CCCFs. The findings could also be included in the CoG's guidance to help county climate change units improve how CCCFs are established and adaptation is mainstreamed. resilience of development outcomes, contribute to a more efficient use of resources, and help avoid investments that unintentionally lead to maladaptation (Mogelgaard et al. 2018).

Kenya is making progress on building resilience through its National Adaptation Plan (NAP) and by engaging its Council of Governors (CoG) and county governments in the process of establishing County Climate Change Funds (CCCFs) and mainstreaming climate information (e.g., data on risks, hazards, vulnerabilities, and adaptation actions) into County Integrated Development Plans (CIDPs). However, decision-makers there, as in other locations, are finding it challenging to move from planning to implementation. Some Kenyan counties are progressing rapidly toward this goal, while others are lagging.

This paper compares progress across five counties to identify how two of them, Makueni and Wajir, have been able to mainstream adaptation more quickly than the others. It also explores the challenges these counties have encountered and what can be done to address them. It looks at the effectiveness of CCCFs in accelerating mainstreaming of adaptation into planning and the extent to which climate information has been integrated into CIDPs. It also discusses preliminary indications that newly implemented adaptation projects are beginning to build resilience.

This paper complements World Resources Institute's (WRI's) working paper From Planning to Action: Mainstreaming Climate Change Adaptation into Development (Mogelgaard et al. 2018), which identified factors that enable mainstreaming to bridge the "implementation gap" between planning and adaptation activities on the ground. This paper also contributes to WRI's series of case studies on mainstreaming, which include Mainstreaming Adaptation in Action: Case Studies from Two States in India (Dinshaw et al. 2018), which examined mainstreaming in Madhya Pradesh and Uttarakhand in the livestock and forestry sectors, and an internal report to the government of Brazil titled Assessment of the Limits, Challenges, and Opportunities for Adaptation Mainstreaming in Brazilian Cities (Speranza et al. 2018). The Brazilian case study assessed mainstreaming from the national to the city level, including the challenges of implementation. Case studies on mainstreaming adaptation into the health sector and efforts to build coastal resilience while reducing disaster risk will be published in mid-2020. 
RECOMMENDATIONS

- County governments, the Council of Governors, and national government agencies can apply the lessons learned from this research as they work to improve how climate risks are mainstreamed into development plans and speed up implementation of adaptation actions.

- County governments can engage with local universities and extension officers who can offer training to new government staff unfamiliar with climate change. This will help improve retention of climate change knowledge at the county and ward levels.

- County governments can manage funds with due diligence so that disruptions in funding do not hinder adaptation activities from being implemented.

The CoG can share lessons learned and good practices from Wajir and Makueni with environment and development planners across counties and wards so that they can incorporate this information in their planning. One way would be by modifying the existing virtual knowledge-sharing platform to make it more accessible at the ward level. National-level agencies such as the Ministry of Environment and Natural Resources could support this effort.

- Kenyan government representatives could share the experiences of Makueni and Wajir Counties with other countries that are facing mainstreaming challenges. Lessons from Kenya could spark ideas for other countries on how best to mainstream climate risks so that development can be climate resilient.

\section{INTRODUCTION}

Mainstreaming adaptation refers to the incorporation of climate change adaptation objectives into sectoral policies and plans to build resilience-from the national to the local level-in contrast to creating separate policies or programs designed specifically to achieve adaptation objectives (Mogelgaard et al. 2018). Many countries that joined the Paris Agreement on climate change, including Kenya, have committed to mainstreaming as a central feature of their approaches to adaptation. However, despite widespread commitment, on-the-ground resilience building has been slow almost everywhere: Out of a hundred cases of mainstreaming analyzed by Runhaar et al. (2017), only a few have demonstrated that integrating climate risks into plans and policies has led to the implementation of adaptation projects.
Kenya is among the countries most vulnerable to climate change impacts and is one of the least prepared to manage climate risks (ND-GAIN Index 2017). Its arid and semiarid lands, together known as the ASAL region, are increasingly affected by climate change impacts, such as more frequent and severe droughts and floods, making the region the most vulnerable area within the country (PRISE 2016).

Kenya has made considerable progress in mainstreaming adaptation at the national level through its National Adaptation Plan, as well as at the county level with support from its Council of Governors (CoG) and county governments. The national government recognized the need to build resilience in the vulnerable ASAL region by making it the focus of Kenya's second National Climate Change Action Plan (GoK 2018c).

The ASAL region has begun mainstreaming climate change information into its plans and policies. At the county level, information on climate risks, hazards, vulnerabilities, and priority adaptation actions are starting to be integrated into County Integrated Development Plans (CIDPs), while County Climate Change Funds (CCCFs) are being established to provide financial support to counties to propose, prioritize, and implement necessary adaptation actions. This enables county governments to strengthen and reinforce national climate change policies while delivering on local adaptation priorities, which has proved to be essential to enabling progress.

However, despite these positive developments, progress has been uneven: While some counties are moving ahead with planning and implementing adaptation actions, others are moving more slowly in this process. This paper compares progress across five counties to identify how two of them, Makueni and Wajir, have been able to establish CCCFs and mainstream adaptation into their CIDPs more quickly than the other three: Garissa, Isiolo, and Kitui Counties. It also explores the challenges Makueni and Wajir have encountered and what can be done to address them.

\section{Context}

The ASAL region, which composes more than 80 percent of the land in Kenya, is home to nearly 10 million people, as well as approximately 70 percent of the national livestock herd (Odhiambo 2014), despite its aridity (annual rainfall typically varies between 200 and 700 millimeters) (Nduku et al. 2016). Figure 1 shows the location and distribution of ASAL counties. 
Droughts and floods are the leading climatic threats to livelihoods, human health, and the economy in Kenya, and are becoming more frequent and severe due to climate change. Over the past 30 years, flood frequency has increased from an average of less than three events per year in the 1980 s to approximately 10 events per year in the 200os. Droughts have also become longer and more intense over the same time span, often disrupting rainy seasons (GoK 2018c). Although there is some uncertainty, most projections indicate that these trends will continue.

A majority of residents in the ASAL region are highly vulnerable farmers and pastoralists. Their livelihoods depend on increasingly erratic rainfall to water their crops and grow forage for their livestock (UNDP 2012), and their efforts to expand irrigation are hindered by poverty and low technical capacity. Insecure land tenure, land fragmentation, poor natural resource management, and population growth add to the adaptation and development challenges in this region. Women, who manage over 40 percent of smallholder farms and provide up to 80 percent of labor for crop production in Kenya (UNDP 2012), are especially vulnerable to climate change impacts. For example, women in rural areas, particularly the ASALs, already spend up to five hours per day collecting water, which limits their ability to engage in other types of work (UNDP 2012); absent adaptation measures, the time required will likely grow with frequent and more intense droughts. Food insecurity, which is already high in the ASAL region, will likely increase as droughts become more frequent and water becomes scarcer (UNDP 2012), which will exacerbate vulnerability to climate change (USAID 2019).

\section{PURPOSE AND SCOPE OF THE PAPER}

This paper is intended to inform a range of adaptation stakeholders on several issues:

Kenya's Council of Governors, which acts as a secretariat to county governments, is made up of administrators, environmental experts, and county representatives who are responsible for mainstreaming climate information and building resilience at the county level. The $\mathrm{CoG}$ is in a good position to share this paper's lessons learned from fast-moving Makueni and Wajir Counties with other counties that are earlier in the process, and to use this information to strengthen the guidelines it is currently drafting to establish county climate change units and improve the establishment of CCCFs in other counties.
County governments charged with implementing CIDPs will find insights into how integrating climate information into county planning can lead to on-theground action.

- National agencies such as the National Treasury, Ministry of Environment and Natural Resources, and Ministry of Devolution and ASALs could also benefit from this paper as they work to create enabling environments for mainstreaming adaptation.

The paper can also increase the understanding of donors, development organizations, and nongovernmental organizations on how best to support adaptation mainstreaming at the county level.

Finally, other countries facing similar challenges could gain insights into what is involved in mainstreaming climate information. All of this could accelerate adaptation action on the ground.

\section{Figure 1 | Kenya's ASAL Counties}

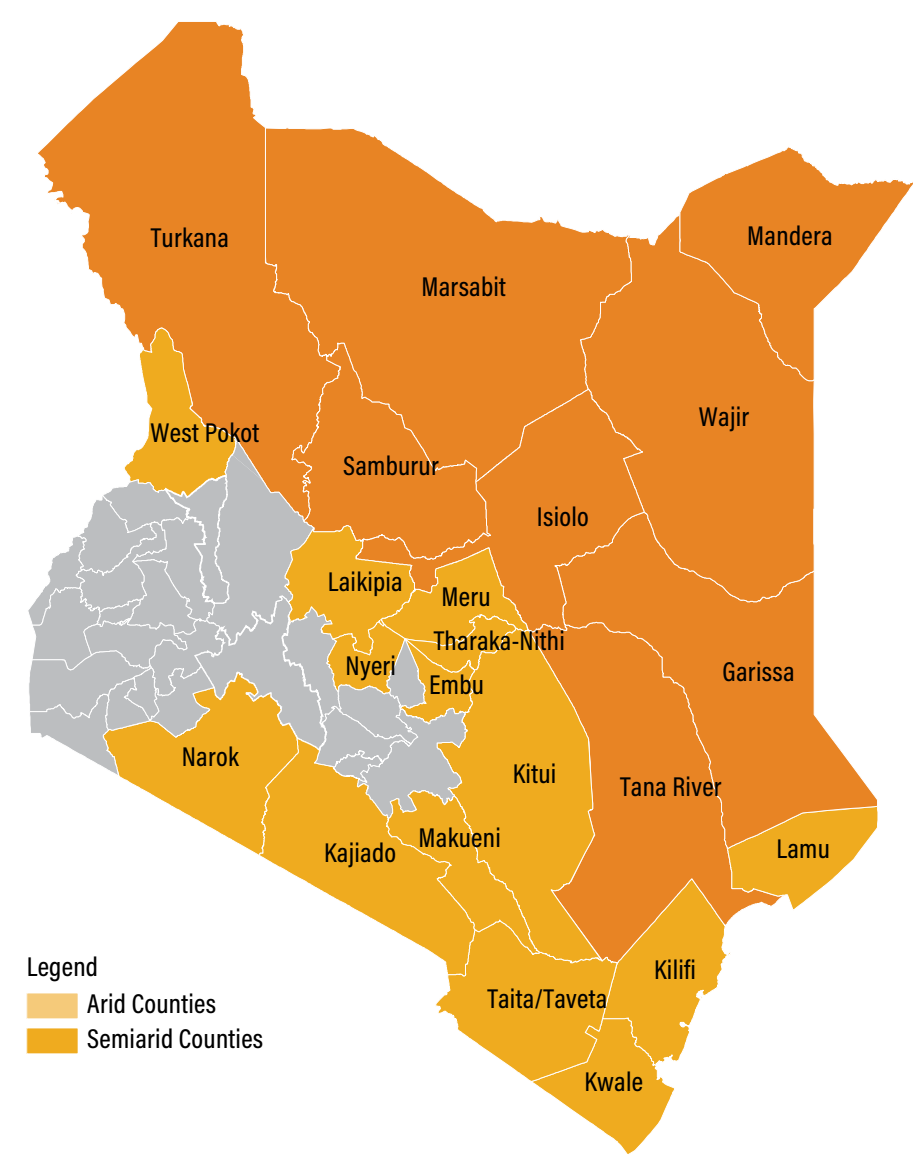

Source: Adapted from PRISE 2016 
Before the paper dives into lessons learned from Makueni and Wajir, the research methodology is explained in Section 3. Section 4 describes how the government of Kenya has mainstreamed adaptation into development plans at the national level, while Section 5 illustrates how CCCFs have helped jumpstart the process of integrating climate information into county development plans. Section 6 provides an analysis of how climate information has been integrated into CIDPs. Sections 7 and 8 delve into lessons learned from Makueni and Wajir, respectively. In these sections, enabling factors and barriers to mainstreaming are identified. The perceived early benefits of implementing CIDPs are also described through examples that focus on how improving access to water is supporting livelihoods that depend on agriculture and livestock. Section 9 summarizes key findings, and Section 10 gives recommendations that CoG can use to strengthen its guidance on how to improve the process of mainstreaming adaptation and establishing CCCFs.

\section{METHODOLOGY}

To understand the dynamics of the progress that Makueni and Wajir Counties have made and the challenges they have faced, this paper focuses on four research questions that emerged out of discussions with the CoG:

1. Has the establishment of CCCFs been an effective mechanism for accelerating the process of integrating climate information (e.g., data on risks, hazards, vulnerabilities) into CIDPs?

2. To what extent has climate information been integrated into CIDPs to enable the identification and prioritization of adaptation activities that will improve resilience to current and anticipated climate impacts?

3. What were the key factors that enabled this to happen, and what are the main challenges in this process?

4. Are there any early indications that implementing the adaptation components of the CIDPs has improved resilience?

To answer these four research questions, we first reviewed relevant Kenyan national-level policies and plans to understand the context and emphasis on mainstreaming adaptation at the national level, as well as the structure and intended functions of the CCCFs and CIDPs.
We also reviewed literature on mainstreaming adaptation from the national to the local level. Key studies that shaped this research included Runhaar et al. (2017), which analyzed a hundred cases of mainstreaming adaptation and found that, despite widespread commitment to this approach to adaptation, only a few cases illustrated that integrating climate risks into plans and policies had led to actual implementation of adaptation projects. In addition, Dinshaw et al. (2018) analyzed mainstreaming efforts by two state governments in India and found the following: programmatic mainstreaming may be more financially sustainable than project-specific mainstreaming; supportive policy frameworks have an important role to play in scaling up the mainstreaming efforts; and capacity building and coordination are key to moving from planning to action. Finally, the enabling factors and challenges of mainstreaming identified in Mogelgaard et al. (2018) influenced the research design as well.

Next, we analyzed the CIDPs of five Kenyan counties to assess the extent to which they contained information on climate change impacts and adaptation priorities. Whether and how the presence of this information had changed between the plans' first (2013-17) and second (2018-2022) iterations was analyzed using quantitative key term searches. Each document was searched to count the number of times keywords including "mainstream," "climate information," and "CIS" (an acronym for climate information services) appeared. Keywords found in titles or executive summaries were not included in the counts.

The documents from all five counties included climate information and adaptation priorities in relation to agriculture, enabling comparisons between them, so agricultural adaptation strategies were also selected for further comparative analysis. We read through the documents and noted examples of such actions. Many documents mentioned the same agricultural adaptation project, proposal, or strategy multiple times, but each separate initiative was counted only once (e.g., if a document listed 10 dams built for irrigating farms, only one was counted to represent the adaptation measure of adding water catchments for agricultural irrigation).

CIDPs in counties where CCCFs have been established were compared with those that do not yet have such funds to better understand whether their creation influenced the types of climate-related information that was integrated into the plans. These analyses provided the data behind Table 2, which compares how each county integrated climate information into the most recent version of its CIDP. 
In addition to compiling information on general mainstreaming, climate, and agricultural adaptation strategies, we also collected examples of how climate change was integrated into specific sectors in Makueni's and Wajir's CIDPs. These examples provide explicit references to climate change that have led to or are intended to lead to the implementation of adaptation actions within the county. These examples were used to develop Tables 2 and 3 , which provide a more detailed look at how mainstreaming adaptation and climate information were included in various sectors, and how consideration of climate change in the sectors changed over time.

In addition to the quantitative keyword analysis, we used a semi-structured questionnaire to guide in-depth, face-toface interviews to answer the four research questions, and verify the findings from the CIDP analysis. We discussed the interview protocol with the CoG before administering it to ensure the questions were applicable in the Kenyan context and would be useful in meeting research objectives. Prior to all interviews, the research objectives were explained to the interviewees, who were assured that their responses would be kept confidential before they gave their consent to be interviewed.

Interview questions related to enabling factors and challenges of mainstreaming were based on five components, or "gears," that work together to support adaptation mainstreaming (Mogelgaard et al. 2018, see Appendix A). These gears include having useable policy frameworks, sustained leadership, coordination mechanisms, accessible information and tools, and supportive financial processes. The questionnaire left space for additional enabling factors and challenges to be identified. The interview questionnaire can be found in Appendix B.

Questionnaires were administered to a diverse range of stakeholders involved in adaptation and development planning. At the national level, six respondents represented the CoG Secretariat, National Treasury, Climate Change Directorate (within the Ministry of Environment and Natural Resources), Adaptation (Ada) Consortium, and the Ministry of Devolution and ASALs. Although other ministries play important roles in mainstreaming adaptation, such as the Ministry of Agriculture, Livestock, Fisheries, and Irrigation; Ministry of Water and Sanitation; and Ministry of Energy, they were not interviewed because the CoG suggested focusing on the ministries that have a more direct influence on county-level mainstreaming.
At the county level, five respondents from the Makueni and Wajir county governments were initially interviewed. A snowball sampling method was then used, wherein initial respondents encouraged others to be interviewed, which led to a total of 11 individual interviews and one group discussion with six people in Makueni. It was not possible to organize a group discussion in Wajir as travel to the county was prohibited due to security concerns.

Responses to the interview questions were transcribed and grouped to address the four key questions of this research. Grouping common answers helped to identify and verify key themes. This also helped us classify responses that were outliers, although unique answers were included in the analysis to shed light on issues that were not covered by other respondents. Preliminary findings were presented to the CoG and Ada Consortium for their feedback and are incorporated throughout the paper.

\section{Limitations}

While a diverse group of respondents were interviewed, the small sample size is a limitation of this research. Conducting a larger number of interviews with a broader range of stakeholders from additional Kenyan counties would have provided additional perspectives, but time and resource constraints prevented this. Despite this, preliminary lessons learned and examples were captured to provide timely suggestions to inform the CoG's ongoing process of expanding and strengthening the use of CCCFs to spur incorporation of climate change information and solutions into CIDPs.

The assessment of the early effects of integrating climate information into CIDPs is based on the limited set of interviews, rather than on rigorous evaluations or impact assessments. It was not possible to conduct these types of analyses because the implementation process has only recently begun and its full effects cannot yet be measured. Also, the paper focuses on the process of mainstreaming at the county level, rather than on how finance flows to the local level, so that issue was not investigated. 


\section{CLIMATE CHANGE ADAPTATION POLICY/PLAN}

National Climate Change Response Strategy (2010)

National Climate Change Action Plan I (2013-17)

Intended Nationally Determined Contribution (2015)

Climate Change Act (Number 11 of 2016)

National Adaptation Plan (NAP) 2016

National Climate Change Framework Policy and Act (2018)

National Climate Change Action Plan II (2018-2023)

\section{HOW MAINSTREAMING ADAPTATION IS ADDRESSED}

The strategy was the first national policy document that advanced integration of climate change adaptation and mitigation into all of Kenya's government planning, budgeting, and development objectives. ${ }^{a}$

The plan helped operationalize the National Climate Change Response Strategy (2010). It supports the integration of climate change adaptation into sector policies, development, budgeting, and planning at all levels of government ${ }^{b}$

Kenya's Intended Nationally Determined Contribution states that its enhanced climate resilience will contribute to the attainment of its Vision 2030 development blueprint by mainstreaming climate change into Medium-Term Plans and implementing adaptation actions. ${ }^{c}$

The act adopts a climate change mainstreaming approach that includes integrating climate change considerations into development planning, budgeting, and implementation in all sectors and at all levels of government. It also established the national Climate Change Fund, ${ }^{d}$

The NAP highlights the importance of integrating adaptation into development planning and budgeting at the national and county levels and suggests how vulnerability to climate change impacts can be minimized. The plan requires counties to develop finance mechanisms and tracking systems for adaptation. ${ }^{\mathrm{e}}$

The framework policy ensures integration of climate change considerations into planning, budgeting, implementation, and decision-making at the county and national levels and across all sectors. ${ }^{\dagger}$

The plan fulfills the Climate Change Act, focusing on integrating mitigation into 6 sectors and adaptation into 14 sectors. ${ }^{9}$

\section{MAINSTREAMING ADAPTATION AT THE NATIONAL LEVEL}

The government of Kenya has taken several measures to mainstream adaptation at the national level, starting in 2010 when it first began to address climate change as part of national policy (Lovell et al. 2019). Table 1 provides a summary of key climate change legal and policy frameworks and how they promote mainstreaming climate change adaptation.

In addition to including adaptation in the climate-focused legal and policy documents described in Table 1, Kenya's government has taken steps to integrate adaptation into development policies and plans, including Vision 2030, Kenya's development blueprint, which acknowledges climate change and the risks it poses to the country's continued progress and growth. The national government has also mainstreamed adaptation into its MediumTerm Plans (MTPs) II (2013-17) and III (2018-2022) for development. MTP III in particular mandates that climate change be included and has a specific section on its significance. This plan identifies policies that include climate change adaptation, such as the Climate Smart Agriculture Strategy (2016), Forest Conservation and Management Act (2016) and National Forest Programme (2016-2030), National Drought Management Authority Act (2016), Water Act (2016), Draft Energy and Petroleum Policy (2015), Integrated National Transport Policy, Draft National Solid Waste Management Bill (2017), and National Spatial Plan (2015-2045).

In addition, "greening" initiatives, some of which have relevance for climate change adaptation, are being implemented in sectors such as manufacturing, agriculture, tourism, infrastructure, and health. Furthermore, the National Finance Policy has led to the establishment of legal, institutional, and reporting frameworks to access and manage climate finance so that adaptation projects can be implemented on the ground. 


\section{COUNTY CLIMATE CHANGE FUNDS AND CLIMATE INFORMATION SERVICES PLANS}

The aggregation of these national-level climate and development policies and plans provided the framework needed to establish the CCCFs, which were created for two main reasons: The first was to enable faster financing of projects to address the climate impacts in the ASAL region, according to the CoG and the Climate Change Directorate. The second was to provide counties with additional funds needed to fully implement climate change actions for both adaptation and mitigation-according to the $\mathrm{CoG}$ and the National Treasury, funding from the national government to build capacity and provide technical support at the county level is insufficient for this. Additional information on the piloting and eventual expansion of CCCF mechanisms can be found in Appendix C.

A number of organizations were involved in the establishment of the CCCFs through the Adaptation (Ada) Consortium, which is a multipartner entity comprising the Council of Governors, Kenya's National Drought Management Authority, the Kenya Meteorological Department, the United Kingdom (UK) Met Office, Christian Aid, and the International Institute for Environment and Development. In-county partners include Anglican Development Services-Eastern in Kitui and Makueni, Arid Lands Development Focus in Wajir, Womankind Kenya in Garissa, and the Resources Advocacy Programme in Isiolo, which was later replaced by the Merti Integrated Development Programme. CARE International was briefly a member. Together, they helped establish the CCCF mechanism. It was initially supported by the UK Department for International Development through its Strengthening Adaptation and Resilience to Climate Change in Kenya Plus program, which ran from 2013 to 2018.

The CCCFs consist of blended finance from international climate funds, development partners, the private sector, and national and county budgets to support, pilot, and scale climate change action. The funds work through the government's planning and budgeting system and are linked to the National Climate Change Fund, which was established under the Climate Change Act of 2016. Counties that establish CCCFs can use funds from the National Climate Change Fund, as well as funds from the county, to identify, prioritize, and finance investments to reduce climate risks and implement adaptation actions through a structured process of transparent, communitybased adaptation planning at the county and ward levels.
Figure 2 | Counties with County Climate Change Funds

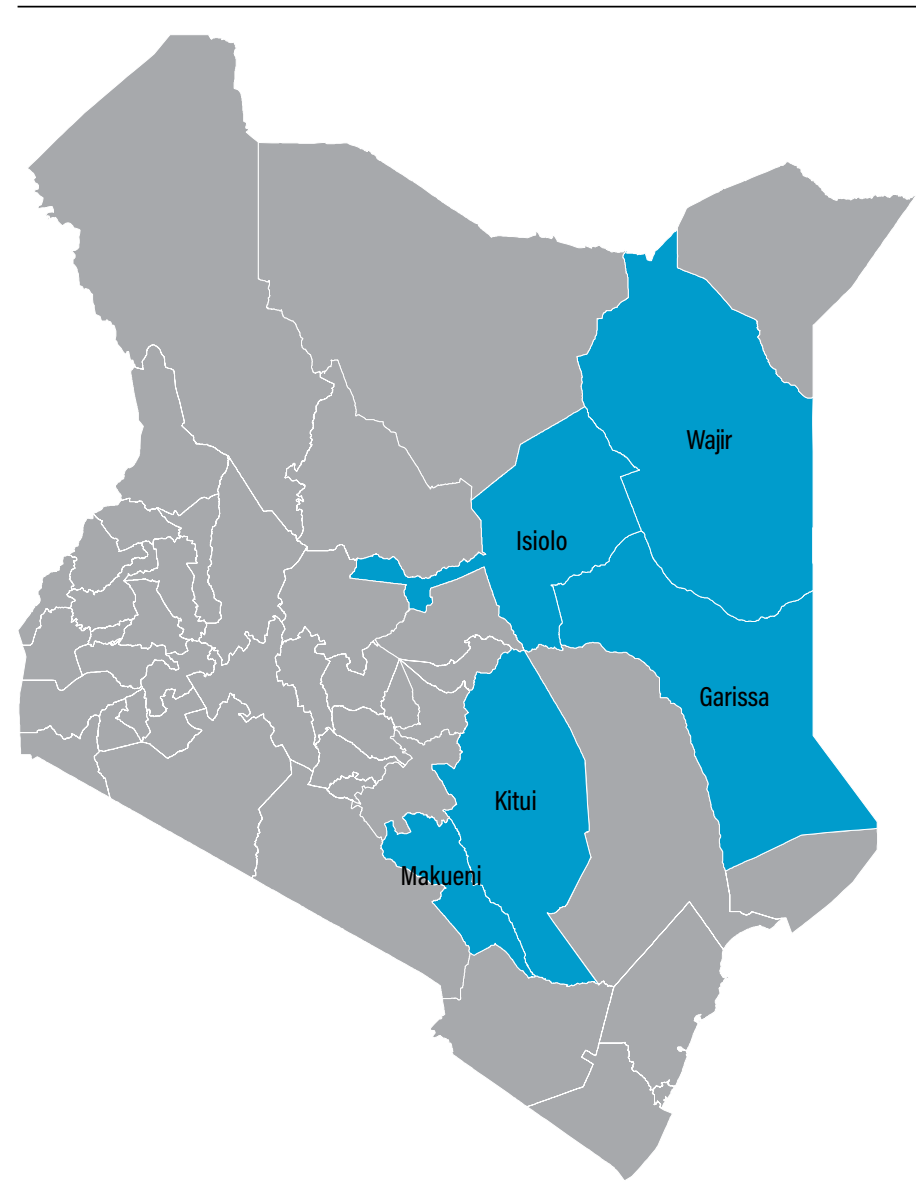

Source: Adapted from Ada Consortium 2016.

CCCFs are governed by a county-level board that approves proposals prepared by the county governments in consultation with ward representatives and communities. Proposals to the CCCFs to implement adaptation actions must meet several criteria by describing how they

1. demonstrate that the adaptation actions they propose will benefit many;

2. support the local economy and livelihoods;

3. are relevant to building climate change resilience;

4. build relationships and trust among stakeholders;

5. are developed through stakeholder consultation;

6. are viable, achievable, and sustainable; and

7. are cost-effective (Murphy and Orindi 2017). 
Thus far, CCCFs have been established in five counties: Makueni, Wajir, Garissa, Isiolo, and Kitui (see Figure 2). Makueni and Wajir Counties established CCCFs first, in 2015 and 2016, respectively.

County governments commit a certain percentage of their annual development budgets to the funds-for example, 1 percent in Makueni and 2 percent in Wajir. This commitment allows for domestic resources to be allocated for climate-related efforts and establishes the necessary mechanisms and institutions for applying for and receiving climate finance.

The process of integrating climate information begins with developing a climate information services (CIS) plan for each county, which includes climate information provided by the Kenya Meteorological Department downscaled to the county level (Ada Consortium 2015c). In Makueni, climate information is translated into the local Kamba language, while in Wajir it is translated into Somali and Borana for greater uptake. Monthly and seasonal forecasts are downscaled from national forecasts and are supplemented by local and indigenous knowledge to improve understanding of the factors that affect the local climate and projected implications for local livelihoods (KMD 2017).

Figure 3 shows how CCCFs, CIS, and CIDPs are linked: Once a CCCF is established, it opens up access to and integration of climate information into the CIDP, as indicated by the yellow arrow. Communities are required to demonstrate that they have used climate information to identify adaptation activities in order to receive funds from the CCCF to implement these activities (Ada Consortium 2015b). These connections between the CCCF, climate information, and CIDP are what enables adaptation

\section{Figure 3 | Connection between CCCFs, CIS, and CIDPs}

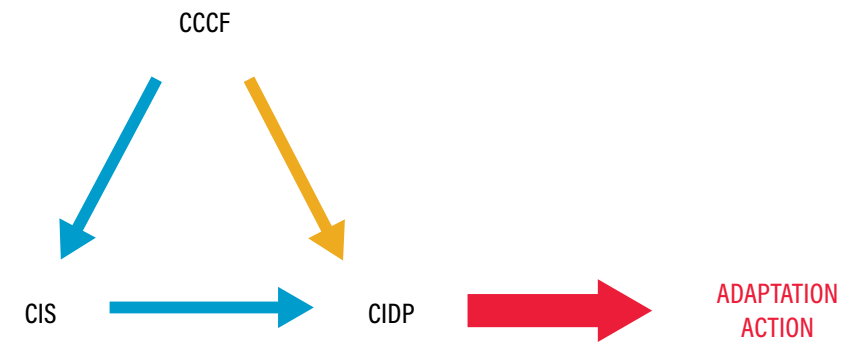

Notes: CCCF stands for County Climate Change Fund, CIS for climate information services, and CIDP for County Integrated Development Plan.

Source: Authors action to take place, as will be demonstrated throughout the paper and particularly in Sections 7 and 8, where the experiences of Makueni and Wajir Counties are described.

Once counties receive downscaled climate information, county- and ward-level climate change planning committees made up of county government officials and residents are trained by the Ada Consortium on how to apply it. Training on how to use climate information in decision-making enables committee members to effectively communicate this information to others (Ada Consortium 2015b). The training methods used appear to be quite effective: An evaluation of a training by Ada and the National Disaster Management Agency found that 95 percent of participants said they felt ready to use the information to make decisions (Ada Consortium 2015b). The committees then use this information to prioritize projects that address local climate variability and extreme events (IIED 2013).

The Ada Consortium also supports counties in conducting participatory resilience planning among county- and ward-level committees to identify adaptation activities, which involves stakeholder engagement with the county government, partnering organizations, and local community members in wards (Ada Consortium 2015a). The resulting county- and ward-level resilience assessments become part of the CIS plan, which is used to integrate climate information and adaptation activities in CIDPs. Therefore, training on how to use climate information and conduct resilience planning is a key enabling factor when it comes to integrating climate information and adaptation activities into CIDPs.

In addition to building capacity on how to use climate information and conduct resilience planning, the Ada Consortium stated that designating climate change officers at the county level to support integration of adaptation planning and coordinate climate change activities has been critical to integrating climate change into CIDPs. 


\section{ANALYSIS OF COUNTY INTEGRATED DEVELOPMENT PLANS}

Kenya's Climate Change Act of 2016 requires county governments to mainstream climate change actions, interventions, and duties into the County Integrated Development Plans. CIDPs across Kenya's 47 counties provide a framework for development over a five-year period. The plans aim to coordinate the work of the county government in order to improve people's quality of life and contribute toward devolution (Murphy and Orindi 2017). CIDPs contain specific goals and objectives; implementation plans; provisions for monitoring and evaluation; information on investments, projects, and initiatives; maps; and a resource mobilization framework. This information is intended to reflect the strategic priorities for the county government and inform county budget priorities for the given five-year period (GoK 2018b). The first round of CIDPs covered years 2013-17, and the current CIDPs are in place for 2018-2022. CIDP development guidance requires that the United Nations Sustainable Development Goals, climate risks, and climate actions be included.

We analyzed the CIDPs from Makueni and Wajir-the two counties that have fully established CCCFs-and Garrisa, Isiolo, and Katui-three counties that established CCCFs after Makueni and Wajir and are at the early stages of implementation-to assess the extent to which their CIDPs incorporate climate information. The CIDPs of all five counties thoroughly describe the current effects of climate change in the respective counties and how those effects manifest and impact the lives of the people (e.g., flooded roadways, reduced agricultural yields, and reduced access to water). The CIDPs also mention how impacts will be exacerbated as climate change progresses but do not provide detailed information on future projections or how to plan beyond the five-year period. Additionally, all plans mention some version of adaptation strategies that have already been undertaken in the county to combat the effects of climate change. Each plan also presents adaptation strategies that the county plans to implement in the next five years. These strategies range from planting drought-resistant crops to promoting rainwater harvesting, among other measures.

The greatest disparity among the county plans was in the level of technical specificity with which these strategies are presented. To make comparisons across counties uniform and manageable, three key aspects of climate adaptation planning were selected for analysis: mainstreaming climate change across sectors and beyond environmental departments; using climate information; and linking adaptation to agricultural development. Table 2 illustrates some of the differences between the first and second CIDPs across all five counties by demonstrating changes in the frequency with which these topics were mentioned. Green rows indicate that these topics were mentioned one or more additional times in the 2018-2022 plan than in the 2013-17 plan; yellow rows indicate that the topics were mentioned the same number of times in both plans; and red rows indicate that the topics were mentioned fewer times in the 2018-2022 plan than in the 2013-17 plan, signifying a reduced focus on adaptation. Though the number of times a topic was mentioned does not directly translate to a better understanding or greater integration of climate information into development plans, we found that when a CIDP mentioned a particular topic many times, it was often accompanied by greater detail than when a plan did not mention the topic as often.

Overall, the analysis depicted in Table 2 indicates that Makueni and Wajir Counties have developed more detailed strategies over time for each of the topics analyzed. While all counties mentioned mainstreaming climate change information and/or adaptation in some capacity in their 2018-2022 plans, the CIDPs of Makueni and Wajir Counties displayed a growing understanding of the process and benefits of mainstreaming throughout their county governments, rather than only within environmental departments and programs. Mainstreaming was not explicitly mentioned in Makueni's 2013-17 plan but was listed as an economic empowerment priority in its 2018-2022 plan. Wajir's 2018-2022 plan calls for increasing response capacity and minimizing losses from climate hazards by strengthening disaster preparedness and response, which was not included in its 2013-17 plan. Makueni and Wajir also delineated plans to integrate climate change into various sectors and operations. In contrast, Garissa, Isiolo, and Kitui Counties focused on mainstreaming climate change within their respective environmental departments or programs, rather than across sectors.

The use of climate information was described in greater detail in the more recent CIDPs of Makueni, Wajir, and Garissa than in those of Isiolo and Kitui, which commonly presented ideas with little to no linkages to climate information or detail on how those plans could be achieved. Makueni's 2018-2022 CIDP describes enhancing its climate information systems to better equip 
Table 2 | Sample of Adaptation-Related Changes between 2013-17 and 2018-2022 CIDPs in Makueni, Wajir, Garissa, Isiolo, and Kitui Counties

\section{3-17 CIDP}

MAKUENI COUNTYa,b

Mainstreaming

Climate information

Agricultural adaptation

\section{8-2022 CIDP}

Use drought-tolerant crops

Not explicitly mentioned

Not explicitly mentioned
Mainstreaming climate change into county development is a priority for economic empowerment

Strengthen climate information systems to inform communities for decision-making

Promote climate-smart agriculture practices

Use drought-tolerant or drought-resistant crops

Enhance livestock, dairy, and pasture development and community training programs

\section{WAJIR COUNTYG,d}

Climate information

Mainstreaming planning and budgeting processes for drought risk reduction, ending drought emergencies, and climate change adaptation is mentioned more often in the plan

Use climate information to train communities on climate-smart livestock farming

Train farmers on climate risks and information

Promote modern pastoralism, which is adaptive to climate
Mainstreaming

Agricultural adaptation

Use drought-resistant crops

Mainstream planning and budgeting processes for drought risk reduction, climate adaptation, and ending drought emergencies Not explicitly mentioned

GARISSA COUNTY

Mainstreaming

Not explicitly mentioned

Climate information

Not explicitly mentioned

\section{Agricultural adaptation}

Strengthen early warning system

\section{ISIOLO COUNTYg, h}

Mainstreaming

Climate information

Agricultural adaptation
Not explicitly mentioned

Expresses need for more well-adapted livestock and briefly discussed in relation to other sectors Use drought-resistant crops

Invest in agricultural skills development and enhance awareness of climate information

Department of Environment, Energy, and Natural Resources proposes updating procedures and standards to mainstream climate risks Climate risk information program to build county risk profiles and enhance adaptation

Promote crop rotation and diversification

Climate change is considered a crosscutting issue Mainstream dry land issues into all county development plans and

policies

Mainstream climate adaptation into planning at all levels by strengthening community resilience

Mainstream climate change into all water management plans and actions

Not explicitly mentioned

Introducing climate adaptable livestock breeds is a priority for the Ministry of Agriculture, Livestock, and Fisheries

Ministry of Agriculture, Livestock, and Fisheries proposes introducing climate-smart technology 
Table 2 | Sample of Adaptation-Related Changes between 2013-17 and 2018-2022 CIDPs in Makueni, Wajir, Garissa, Isiolo, and Kitui Counties (Cont'd)

\begin{tabular}{|c|c|c|}
\hline KITUI COUNTYij & & \\
\hline Mainstreaming & $\begin{array}{l}\text { Climate adaptation is a priority for the Ministry } \\
\text { of Environment, Energy, and Mineral Investments } \\
\text { Development }\end{array}$ & Climate change is listed as a priority area of the development agenda \\
\hline Climate information & $\begin{array}{l}\text { Instituting a climate information system is an } \\
\text { objective of the Ministry of Environment, Energy, } \\
\text { and Mineral Investments Development }\end{array}$ & Not explicitly mentioned \\
\hline Agricultural adaptation & Promote drought-resistant crops & $\begin{array}{l}\text { The proposed Kitui Conservation Agriculture Programme aims to build } \\
\text { farmers' adaptative capacities and climate resilience }\end{array}$ \\
\hline
\end{tabular}

Note: CIDP stands for County Integrated Development Plan.

Sources: a. GMC 2013; b. GMC 2018c; c. CGW 2013; d. CGW 2018b; e. CGG 2013; f. CGG 2018; g. CGI 2013; h. CGI 2018; i. CGoK 2013; j. CGoK 2018.

communities for decision-making. Wajir's 2018-2022 plan details the use of climate information to train communities on climate-smart farming and climate risks. Garissa's 2018-2022 plan outlines a climate risk information program to create county risk profiles and ultimately enhance adaptation to climate change. Isiolo did not mention climate information in either plan. Kitui's 2013-17 plan mentioned instituting a climate information system, but climate information was not explicitly mentioned in its 2018-2022 plan.

Even though the five counties have integrated climate information into their CIDPs at various levels, building capacity to understand climate information and expertise to integrate it into development plans is an ongoing process. According to the Ada Consortium, there is continuous and considerable staff turnover in counties, and new governors and executives often enter office without fully understanding climate change issues. This poses the risk that climate information may not be consistently integrated into future CIDPs if those with knowledge of climate information leave. Interviewees from both the Ada Consortium and the National Treasury agree that this will require continuous capacity building within counties, human capital to conduct the trainings, and financial resources to support continuous capacity building and integration of climate information into development planning.

\section{Regarding linking climate risk and adaptation to} agricultural development plans, Makueni's 20182022 plan outlines a total of eight strategies to increase agricultural production and provides supporting programs or projects for each. Wajir's updated CIDP mentions plans to integrate its climate information system with the agricultural sector to train farmers on climate risk and climate-smart agricultural practices. Isiolo's 2018-2022 plan introduces climate-adaptable livestock breeds and "climate-smart technology," though little detail is offered for these strategies. Garissa's 2013-17 plan encourages the use of drought-resistant crops, while the 2018-2022 plan promotes crop rotation and diversification. Kitui's 201317 plan promotes using drought-resistant crops, while the 2018-2022 plan mentions building adaptive capacity and resilience to combat drought.

In addition to the three key aspects of adaptation planning the analysis focused on, we noted differences between a few additional features of some plans. Garissa's, Isiolo's, and Kitui's 2018-2022 plans all included an intention to adopt a climate financing mechanism in the future. Garissa's Department of Environment, Energy, and Natural Resources listed a county climate change fund as a key outcome of its climate change program, as did Isiolo's Energy and Climate Change Programme. Kitui's Climate Change Programme plans to enact legislation to establish a mitigation and adaptation fund.

\section{LESSONS LEARNED FROMI MAKUENI COUNTY}

\section{Makueni County's CCCF and CIDP}

In Makueni County, rains typically come twice a year, with the heavier rainy season occurring from October to December and the lesser rains occurring from March to May. However, rainfall is becoming increasingly erratic and unreliable in Makueni (Muema et al. 2018). Historic 
rainfall records from the Kenya Meteorological Department depict drought conditions across the county over the past three decades. At the same time, Makueni has experienced an increase of $10^{\circ} \mathrm{C}$ in mean temperature since 1981 with some days over $35^{\circ} \mathrm{C}$ (MoALF 2016).

Although most of Kenya has historically been prone to droughts, regions of Makueni that were once agriculturally productive are now much less so (Richard et al. 2012). Along with droughts, Makueni has historically been threatened by seasonal floods, which often occur during the greater rainy season (MoFE 2016). Historical weather analyses demonstrate that droughts and floods have long been significant hazards in Makueni County. However, since 1981, temperatures and extreme heat stress have increased and rainy seasons have become more uncertain and variable (MoALF 2016). These droughts and floods have destroyed crops, damaged irrigation systems, and led to loss of farm equipment and livestock. These impacts undermine food security and reduce incomes in communities heavily reliant on rainfed agriculture (IFRC 2018; Nduku et al. 2016).

\section{Table 3 | Mainstreaming Adaptation across Sectors in Makueni County}

\begin{tabular}{|c|c|c|}
\hline SECTOR(S) & 2013-17 PLANa & 2018-2022 PLANb \\
\hline Agriculture & $\begin{array}{l}\text { Promote drought- } \\
\text { resistant crops }\end{array}$ & $\begin{array}{l}\text { Increase agricultural production } \\
\text { by enhancing farmer skills and } \\
\text { capacities and adopting modern } \\
\text { farming methods; promote the } \\
\text { production of drought-tolerant } \\
\text { crops as well as dairy, meat, and } \\
\text { honey }\end{array}$ \\
\hline $\begin{array}{l}\text { Water and } \\
\text { sanitation }\end{array}$ & $\begin{array}{l}\text { Water projects includ- } \\
\text { ing roof catchments, } \\
\text { storage tanks, and } \\
\text { those to improve ac- } \\
\text { cess to water }\end{array}$ & $\begin{array}{l}\text { Invest in rainwater harvesting, } \\
\text { storage, and distribution; con- } \\
\text { duct water resource mapping; } \\
\text { develop a water master plan }\end{array}$ \\
\hline $\begin{array}{l}\text { Forestry; } \\
\text { education }\end{array}$ & $\begin{array}{l}\text { Institute tree planting } \\
\text { projects, especially at } \\
\text { schools }\end{array}$ & $\begin{array}{l}\text { Train and educate women and } \\
\text { youth in agroforestry projects }\end{array}$ \\
\hline $\begin{array}{l}\text { Agriculture; } \\
\text { climate } \\
\text { information }\end{array}$ & $\begin{array}{l}\text { Strengthen climate } \\
\text { information and early } \\
\text { warning systems }\end{array}$ & $\begin{array}{l}\text { Improve climate change } \\
\text { insurance for livestock and } \\
\text { agriculture; strengthen climate } \\
\text { information and early warning } \\
\text { systems }\end{array}$ \\
\hline
\end{tabular}

Sources: a. GMC 2013; b. GMC 2018c.
According to the $\mathrm{CoG}$, the driving force behind setting up the CCCFs was to be able to more quickly mobilize funding needed to minimize the impacts of climate change. A Makueni County official noted that applying for external sources of adaptation funding is time consuming, with many requirements that need to be fulfilled before a proposal can be submitted. Officials say they are unable to wait to receive external funding to implement adaptation measures when poverty exacerbated by climate change is growing and more people are unable to increase their agricultural yields due to drying conditions and increasing temperatures. In response, Makueni County set aside 1 percent of its annual development budget to address climate change issues. This includes both adaptation and mitigation measures that the county will take. In fiscal year 2017-18, Makueni's total development budget was $\mathrm{KSH} \$ 3.58$ billion ( $\sim \mathrm{US} 34$ million), leaving KHS $\$ 35.8$ million ( US\$344,00o) to focus on climate change (GMC 2018a).

Creating the CCCF seems to have enabled the integration and financing of adaptation activities across multiple sectors in Makueni's 2018-2022 CIDP. Although mainstreaming climate change was not explicitly mentioned in Makueni's 2013-17 plan, it is listed as an economic empowerment priority in its 2018-2022 plan. While Table 2 provides a synopsis of how adaptation action has been mainstreamed across the CIDPs of all five counties analyzed, Table 3 provides more specific information on how adaptation mainstreaming has occurred across multiple sectors in Makueni County.

\section{Enabling Factors and Challenges of Mainstreaming in Makueni}

While building capacity on how to use climate information has been critical, as discussed in Section 4, political leadership has also been a key enabling factor in mainstreaming adaptation. The governor of Makueni County, Professor Kivutha Kibwana, played a key role in establishing the CCCF and integrating climate change into the CIDP and sectoral plans. Governor Kibwana has also been a national leader through his previous roles as minister for defense, minister for land and settlements, and minister for environment and natural resources; a former member of parliament for the Makueni Constituency; and advisor to President Mwai Kibaki. Governor Kibwana's long track record as a strong advocate for environmental issues enabled him to influence county officials to address climate change issues. He has also been able to inspire faith leaders in the county to discuss climate change with 
citizens, to ensure that it is a community priority and discussed in everyday life.

A challenge that Makueni faces, despite having strong leadership, is not being able to easily share information on climate change impacts and adaptation measures across the county. Although CoG's Maarifa Centre established the Maarifa Platform as a knowledge-sharing and online learning platform for capturing and sharing lessons and innovations across 47 county governments ( $\mathrm{CoG} 2020$ ), documentation and knowledge sharing generally occur only among government officials at the national and county levels, rather than at the ward level, where CIDP projects are typically identified and implementation must take place. The platform is of limited benefit for planning because few ward-level officials are aware of it or can access it due to limited internet connectivity, nor does it capture lessons at the ward level on how to integrate adaptation into planning and prioritize adaptation projects. Without ward-level knowledge sharing, it will be difficult for local officials to learn about best adaptation practices that could be integrated into future CIDPs, catalyze prioritization of adaptation projects and speed implementation, and scale projects to benefit people across the county.

\section{Perceived Early Impacts of and Challenges with Implementing Adaptation Activities}

As previously mentioned, the CCCF has helped finance adaptation activities in the CIDP across multiple sectors. These include activities related to conserving and distributing water to minimize droughts and improve agricultural production in this dry region. Projects that have been implemented include rainwater harvesting, wherein communities store rainwater so households can provide water to livestock or use the water in their home gardens. On a larger scale, the Roads for Water project integrates water harvesting for agricultural use with road design and construction, allowing for rainwater to be drained from roads and diverted into agricultural fields (van Steenbergen et al. 2019). CCCF funds have also been used for projects to improve water retention by creating sand dams and swamps, which act as sponges to hold water, help control soil erosion (a critical adaptation challenge), and improve water distribution. More people now have access to water throughout the year, which has improved agriculture and reduced farmer-herder conflicts over access to water. Water is also now distributed to conservation areas, so wild animals are less likely to invade farmlands in search of water.

\section{Box 1 | Masue Rock Catchment}

The Masue Rock Catchment is a large-scale project co-

financed by Makueni County and the United Kingdom Depart-

ment for International Development through the Adaptation

Consortium. In April 2017, the Makueni CCCF provided KHS\$5.4

million to construct a rock catchment in the village of Masue.

The rock catchment system successfully reduced water stress

by using naturally occurring rock outcrops to divert rainwater

to a central collection site. The rainwater passes through a

sand and gravel filter before being stored in a covered tank

or reservoir (Esipisu 2016). During times of drought, com-

munity members can collect the stored water and use it for

agricultural and domestic activities. The project has provided

water to over 1,200 people, 3,000 cattle, and 5,000 goats. It

has improved community access to water, made micro-irri-

gation possible, and supported vegetable growing in kitchen

gardens (GMC 2018b). In addition, a boarding school has been

opened now that there is access to water for cooking, growing

food in kitchen gardens, and maintaining sanitary conditions

for students.
CCCF-funded projects can also help achieve the longerterm outcomes in Makueni's 2018-2022 CIDP, which include female empowerment and the reduction of postharvest loss. Women play a key role in implementing adaptation activities that contribute to both of these goals. For example, women have offered to help build sand dams because they were keen to reduce their burden of fetching water. Better access to water has freed women and girls from the burden of walking 10 kilometers each day to fetch it.

Water retained in sand dams has also encouraged women to establish home gardens and plant fruit trees such as mango on their farms, while improved access to weather information also supports these resilience-building efforts. For example, a full day of warm, dry sunshine is required to properly dry mangoes; just a few hours of overcast skies can increase the humidity in drying sheds and discolor the fruit, rendering it unsellable. Makunei's CCCF helped fund a program wherein the Kenya Meteorological Department relays local weather information via SMS text messages to a network of intermediaries, who then communicate the climate information in a language and format that is easily understood by local farmers. The women involved in mango processing use this weather information to avoid post-harvest loss (Langat 2017a). This has especially benefited poor, vulnerable women. 
Despite these successes, Makueni still faces challenges in implementing adaptation activities. It quickly set up the CCCF in 2016, before the National Policy on Climate Finance was finalized in 2018, and is still working to improve fund management and link the CCCF with the National Policy on Climate Finance. According to the National Treasury, waiting for the national-level policy to be established first could have helped guide how the CCCF should be managed and led to better alignment between national- and county-level fiscal policies. This lack of alignment and limited capacity to manage funds has resulted in administrative challenges with mobilizing resources to fund adaptation projects. However, the respondent from the National Treasury acknowledged that formulating national-level policies requires time and resources, and the urgency to address the impacts of climate change means that counties may need to act quickly and not be able to wait. To better align nationaland county-level fiscal policies in the future, the national government asked counties to comment on the National Policy on Climate Finance when it was being drafted. Makueni was the only county that provided comments based on its experiences creating a CCCF, demonstrating that it is keen to align with national policies and improve the CCCF so that finance flows more quickly to adaptation projects and implementation of adaptation activities can happen faster.

\section{LESSONS LEARNED FROM WAJIR COUNTY}

\section{Wajilr County's CCCF and CIDP}

It was urgent that Wajir establish its CCCF and begin adapting to climate change: The county has long been extremely dry, and climate change-related droughts have made water all the more scarce. In Wajir, the annual average rainfall is between 250 and 500 millimeters, most of which falls during the second wet season (July through December). In recent decades, the first wet season (January through June) has seen an increase in droughts and temperatures while the second has been characterized by slight increases in precipitation and temperature. Overall, droughts have become more frequent and intense in Wajir. According to future projections, drought intensity and frequency, along with average annual temperatures, are expected to continue to increase, affecting agriculture and livestock production. These changes threaten 85 percent of household income among nomadic pastoral communities (MoALF 2017). Water stress among these communities has led to poor sanitation and food insecurity.

Wajir County is a leader in establishing its CCCF and integrating climate information into CIDPs. Nine counties, including Makueni, have come to Wajir to learn how to establish a CCCF and integrate climate information into

Table 4 | Mainstreaming Climate Adaptation across Sectors in Wajir County

\section{SECTOR(S)}

Agriculture (crops)

Agriculture (livestock)

\section{Energy}

Information

Agriculture; information; health

Water and sanitation; infrastructure and transportation

Health; agriculture; water and sanitation

\section{3-17 PLANa}

Increase agricultural productivity with farmer trainings on modern farming methods, including greenhouses, irrigation, technology, and drought-resistant crops

Increase livestock production, relieve water stress caused by livestock, and introduce livestock insurance program

Promote renewable and alternative sources of energy

Improve early warning systems

Support livestock insurance program; scale up hunger safety net programs

Construct proper drainage systems and dams; integrate drainage with road network

Combat poverty and hunger by enhancing farming and irrigation

\section{8-2022 PLAN}

Adapt agriculture to climate change through droughtresistant crops, farmer trainings in enhanced information flow, and skills development

Increase livestock production, develop water sources for livestock, scale up the livestock insurance program, and improve rangeland management via policy and resource mapping

Promote wind and solar energy

Enhance climate change surveillance and early warning systems

Improve the Hunger Safety Net Programme

Climate-proof roads to ensure delivery of agricultural, health, and educational services

Enhance food and nutritional security through farming; expand irrigation and harvesting for rainwater for agricultural production 
CIDPs. The Wajir Climate Change Fund Act of 2016 led to the establishment of the county's CCCF. The act mandated that the county government of Wajir set aside 2 percent of its annual development budget for climate change action. Currently, the CCCF in Wajir is financed by the county government, with support from the Ada Consortium. In fiscal year 2017-18, Wajir's total development budget was KHS $\$ 3.7$ billion ( US $\$ 35.4$ million), leaving KHS $\$ 73.5$ million ( US $\$ 708,000)$ for adaptation (CGW 2017).

Table 4 provides a summary of Wajir's 2013-17 and 20182022 CIDPs and the multiple sectors where adaptation has been integrated. As in Makueni, adaptation is integrated most prominently in the agricultural sector. For example, both CIDPs encourage the adoption of new pastoralism practices that will benefit the environment in the long term. Additionally, the 2018-2022 plan mentions training farmers on climate-smart practices and on applying climate risk information to decision-making, rangeland management, and the use of early warning systems.

\section{Enabling Factors and Challenges of Mainstreaming in Wajir}

As in to Makueni, leadership has been a critical enabling factor for mainstreaming adaptation. In Wajir, "opinion leaders" within communities, such as teachers and agriculture officers, have helped others in the county better understand the importance of addressing climate change. These opinion leaders act as knowledge brokers, disseminating messages about addressing droughts and floods. This has helped communities better understand and articulate how the climate has changed over time by referring to hazards and risks, which has enabled adaptation planners at the ward and county levels to better integrate community perceptions into the CIDP.

Another reason Wajir has been able to incorporate more climate information into its 2018-2022 CIDP as compared with its 2013-17 CIDP is the numerous consultations the county government held with a range of stakeholders between the two. In collaboration with the Ada Consortium, the Wajir county government came up with a CIS plan that included a strategy to disseminate downscaled climate information. The county government also used Wajir Community Radio to further distribute climate information across the county (Dimbore 2019). Furthermore, the government took considerable time to develop the 2018-2022 CIDP so it could invite input from climate experts and professionals. It coordinated stakeholder engagement to improve its CIDP with funding from the United States Agency for International Development (USAID) that was channeled through the Ahadi Kenya Trust, a nongovernmental organization focused on environmental health. This funding helped the county government coordinate input into the CIDP through workshops with experts and government departments. The funding also enabled county government officials to fly to Nairobi to discuss how to better integrate climate information into the county's CIDP with additional input from experts and politicians.

Although coordination has been critical, it has not been easy. The Ahadi Kenya Trust provided considerable funding, but ultimately it could finance only a limited number of stakeholder engagement sessions. It was especially challenging to reach out to nomadic pastoral communities that live far apart-spread out across 10 percent of Kenya's land base-particularly the 30 wards in the county that have poor roads and connectivity. Even when the county government was able to acquire input from remote communities, competition among wards for funding made it challenging to assess which adaptation activities should be prioritized in the CIDP.

\section{Perceived Early Impacts of and Challenges with Implementing Adaptation Activities}

As in Makueni, Wajir's CIDP and use of CCCF funds are focused on water. The county's 2013-16 CCCF investment inventory included 12 projects to improve existing water infrastructure to curb water shortages during times of low availability. These projects focused on either rehabilitating water pans or installing solar panels to power pumps at boreholes. For example, the Adan Awale water pan was once filled with silt, and access by people and animals was unrestricted, resulting in contamination. A rehabilitation project funded by the CCCF desilted and expanded the pan, erected fencing, and installed troughs, a piping system, and a storage tank. This regulated access, increased the pan's annual storage capacity, improved water quality, and ultimately reduced water stress in the community. This project improved water access for nearly 22,000 people and provided water for crops and livestock, which are vital to livelihoods in Wajir. In the Arbajahan Ward alone, improved water access has benefitted 6,200 cattle, 37,000 goats, 7,600 camels, and 150 donkeys (CGW 2018a).

Despite these successful projects, Wajir still faces challenges when implementing adaptation activities. A key challenge is the vastness and remoteness of the county. In 2018, the county government held a two-day 
Box 2 | Wajilir-bor Dam

To improve the livestock sector, Waijir's 2018-2020 CIDP called

for the protection and spatial planning of key rangeland

resources, including water. The creation, protection, and

sustainability of water points funded by the CCCF will provide

a stable source of water in or near rangelands (CGW 2018b).

In Wajir-bor, the construction of a dam, complemented with a

water tank, pump, animal trough, and fence, was financed by

the CCCF. This project was chosen by the 13 Wajir-bor Ward

committee members, five of whom are women. Participating

in the selection of such projects gives women more decision-

making power regarding issues related to water scarcity-a

problem that directly impacts the livelihoods of many. This

is especially true for ethnic Somali women in Wajir-bor, who

are traditionally excluded from leadership positions, but have

found a voice working on these projects (Langat 2017b). This

project has helped to regulate access to water and prolong

water storage time, which has enhanced tariff collection and

improved water quality. An estimated 30,000 people now

have access to water and can provide water to 16,400 cattle,

48,100 goats, 6,700 camels, and 200 donkeys that support

livelihoods (CGW 2018a).

Governance Gaps Assessment Conference to identify governance gaps throughout the county and across multiple sectors. One gap commonly identified by the department heads in attendance was the inability to access and deliver services to the entire county due to its size. Delivering services is logistically challenging due to remote settlements and poor connectivity. This also makes delivering services more expensive, rendering the allocation of 2 percent of development funding for climate change adaptation inadequate. The vastness and remoteness of the county has also led to poor relationships between people and their government, weak coordination between actors and wards, imbalanced distribution of resources, inadequate implementation of projects and programs, and duplication of climate change activities (CGW 2019).

\section{FINDINGS}

Four key lessons on mainstreaming adaptation can be learned across Makueni and Wajir:

1. Establishing the CCCFs has been critical in jumpstarting mainstreaming and enabling counties to integrate climate information into CIDPs. It is not only having access to funds that allows mainstreaming to occur, but also having systems in place that build capacity to access and use climate information that is accelerating the process of mainstreaming adaptation. Analysis of CIDPs shows that counties that have fully established CCCFs demonstrate greater integration of climate information and adaptation strategies than those in the early stages of establishing CCCFs. Establishing a CCCF allows counties and wards to receive information and training to understand and use seasonal forecasts, vulnerability assessments, and resource maps and incorporate such information into their CIDPs. Having climate officers in counties also helps the process of mainstreaming. This finding is consistent with both WRI's framework on mainstreaming adaptation (Mogelgaard et al. 2018) and its mainstreaming case study from India (Dinshaw et al. 2018), which found that access to information and tools, which can encompass learning initiatives, training, or access to technical expertise, enables mainstreaming. Knowledge brokers, such as the Ada Consortium and climate officers, are also key in facilitating information-sharing.

\section{Strong leadership is another key to main-} streaming. Having a political leader, such as Makueni County's governor who is passionate about environmental issues, or opinion leaders, such as Wajir County's teachers and agriculture officers who are willing to advocate for such issues, is key to effectively sharing information about climate change and helping communities better understand climate risks. The political leader described in the Makueni case study was able to reach citizens from the national to local level to raise awareness about climate change while making discussions on climate change a part of everyday life. In Wajir, opinion leaders helped climate change issues become more tangible for people in wards across the county. When county governments identify such leaders and work with them to build their capacities to understand and use climate information, there is a higher chance that climate information will be integrated into development plans, leading to the 
implementation of adaptation activities. This finding is supported by the Mogelgaard et al. (2018) framework on mainstreaming, which found that sustained, persistent leadership from inside or outside government can encourage citizens to champion innovative initiatives that accelerate the implementation of mainstreaming commitments.

3. Stakeholder engagement is critical to integrating climate information into CIDPs. For Wajir, incorporating views from experts in Nairobi and nomadic herding communities in remote wards was an important aspect of mainstreaming adaptation. However, acquiring input to strengthen CIDPs requires a considerable amount of time to travel to meet with stakeholders, and also funding, coordination, and technical support. Funding from USAID through the Ahadi Kenya Trust Fund enabled Wajir County officials to travel to communities to conduct stakeholder engagement workshops. Technical support from the Ada Consortium on developing and using the CIS plan to integrate climate information in the CIDP was also critical, and supported with funding from external donors. The WRI framework on mainstreaming (Mogelgaard et al. 2018) and the case study from India (Dinshaw et al. 2018) both emphasize the need for stakeholder engagement as key to the process of mainstreaming.

4. Early indications are that adaptation action is beginning to lead to climate change and development benefits. The Makueni and Wajir county governments perceive that implementing adaptation projects has improved water conservation and access to water year-round in project locations and reduced women's burden of fetching water. These adaptation activities appear to be leading to improved food security and enhancing the ability of rural people to engage in agriculture and livestock production, the key economic activities in these counties.

\section{RECOMIMENDATIONS AND CONCLUSION}

County governments, the CoG, and national government agencies can use the lessons learned from Makueni and Wajir Counties to strengthen the mainstreaming of climate adaptation into development planning in the following ways:

Retain knowledge and capacity so that momentum to incorporate climate information into CIDPs is not lost when staffing changes. Although the Ada Consortium and the National Disaster Management Agency have made significant efforts to build capacity to integrate climate information into CIDPs and apply it to resilience planning, the challenge of retaining these skills and knowledge remains due to high staff turnover. To improve knowledge retention and provide continuous capacity building in counties, county governments could collaborate with local universities and extension officers to provide training for new staff and leaders to maintain the momentum for mainstreaming. The CoG could also facilitate discussions between county governments and universities to create a curriculum to train future climate and development planners on mainstreaming climate change adaptation.

Improve the governance and transparency of fund management so that adaptation activities can be implemented without disruption. Implementation of adaptation activities in Makueni and Wajir has enabled thousands of poor and vulnerable people to gain access to water for their home gardens and for crop and livestock production. To sustain the implementation of adaptation activities, management of the CCCFs needs to be improved. County governments could improve fund management by aligning their fiscal policies with national-level policies to reduce administrative challenges, and also seek support from the national government to manage county funds, which Makueni is attempting to do. These recommendations could be part of the CoG's plan to establish stronger standards for fund management, which would allow adaptation activities to be implemented without interruption. 
Support learning, especially across wards, on how best to implement adaptation activities. Greater effort needs to be made to support cross-ward learning. Because each ward (and county) is responsible for its own planning, wards within and beyond Makueni and Wajir may not be aware of what is being achieved or the challenges others are facing in implementing adaptation activities. This could limit the implementation and scaling up of successful adaptation practices across wards. The CoG could call for Maarifa Centre's online platform to be downscaled to the ward level so that lessons at this scale can be captured and shared with various climate change planning committees across the county and beyond. When wards have access to information on how best to mainstream climate information and on how to plan and implement adaptation action, they will be able to better integrate adaptation into planning. Such learning would be especially helpful for remote parts of Kenya, like certain wards in Wajir, where access to information is limited.

Engage national government agencies in mainstreaming adaptation at the county and ward levels. Agencies such as the National Treasury, Ministry of Environment and Natural Resources, and Ministry of Devolution and ASALs could work with the CoG to approach donors, development organizations, and nongovernmental organizations to raise funding and provide technical support to either improve the existing Maarifa Centre knowledge-sharing platform to incorporate ward-level information, or create a new platform. This recommendation will be more effective as internet access in remote areas improves. Representatives from these national agencies could also share experiences from Makueni and Wajir internationally with other countries that are facing mainstreaming challenges. Lessons from Kenya could spark ideas for other countries on how best to mainstream climate risks so that development can be climate resilient.

Kenya has come a long way in terms of devolving power to counties and empowering them to make decisions regarding adaptation interventions that are best suited for the local context. Considering that the CCCFs were established only three to four years ago, progress has been made quickly to mobilize funds and address urgent climate impacts in Makueni and Wajir Counties. These counties can serve as models for mainstreaming adaptation and provide lessons that other counties establishing CCCFs could consider when planning and implementing adaptation in a way that suits their context. 


\section{APPENDIX A: FACTORS THAT ENABLE IMPLEMENTATION OF MAINSTREAMED ADAPTATION}

The WRI working paper From Planning to Action: Mainstreaming Climate Change Adaptation into Development proposes a conceptual model with five factors that can help close the "implementation gap" by accelerating the move from mainstreaming commitments and plans to implementation on the ground. This model is flexible, given that mainstreaming efforts and the barriers to implementation vary from place to place. Not all five are necessary for bridging the implementation gap in every case; rather, they can work together in various combinations, like a set of gears. In working together to bridge the implementation gap, aspects of one gear can catalyze or accelerate action in others. Furthermore, they do not need to work in a linear fashion; the gears can turn in different directions, with dimensions of one gear fitting into one or more gears at varying points in time (Mogelgaard et al. 2018).

The five gears include the following:

1. Policy frameworks, including political commitments, mandates, or laws that support mainstreaming. Policy frameworks are more likely to catalyze implementation when they contain mechanisms for accountability or enforcement.

2. Sustained, persistent leadership from inside or outside government, including political leaders, bureaucrats, or civil society organizations. Such leadership could manifest in heads of state launching new strategies that encourage mainstreaming, ministries creating new institutions, or citizens championing innovative initiatives that accelerate the implementation of mainstreaming commitments.

3. Coordination mechanisms across sectors and between government departments, such as interministerial steering committees or task forces, that support shared mainstreaming goals. These systems can cut across policy levels, encompass public and private institutions, and encourage ongoing public engagement.

4. Information and tools, which can encompass learning initiatives, training, or access to technical expertise that enables mainstreaming. Knowledge brokers, who can facilitate information-sharing across sectors and policy domains, are critical in bridging the implementation gap.

5. Supportive financial processes that encourage decision-makers to consider climate risks as well as identify, track, or cover costs to adapt. These could include budget expenditure tracking initiatives, budget tagging efforts, or special funds that governments establish to support mainstreaming efforts.

This working paper used these five gears to frame interview questions about what enabled mainstreaming of climate information into county-level planning. The questionnaire, however, left room for respondents to identify additional factors that may influence mainstreaming.

\section{APPENDIX B: INTERVIEW QUESTIONNAIRE}

Objective: The objective of the questionnaire was to explore answers to these three main research questions:

1. To what extent has the County Climate Change Fund been an entry point for mainstreaming?

2. Has the establishment of a CCCF led to integrating climate risks into county development plans?

3. What are the potential or early signs of impact of implementing the CIDP in relation to adaptation action?

These primary research questions were then used to prompt additional details.

\section{Questionnaire}

\section{Main Research Question: To what extent has the County Climate Change Fund been an entry point for mainstreaming?}

1. Could you tell me a little about how the CCCF came about?

2. What are the supporting policies at the national level that enabled such a financial institution to be established?

3. What are the supporting policies at the county level that enabled such a financial institution to be established?

4. What were the reasons for making sure that communities and villages had direct access to the CCCF, rather than the county administration?

5. Has the CCCF helped address droughts and other climate hazards? If yes, in what ways? If no, why not?

6. Has the CCCF helped initiate mainstreaming/integration of climate information (e.g., hazards, risks, impacts, scenarios, vulnerabilities) into other policies at the national level? If yes, in what ways? If no, why not?

\section{Main Research Question: Has the establishment of the CCCF led to integrat- ing climate risks into county development plans?}

7. To what extent has the CCCF led to integrating climate information into the CIDP? Do you think there is a difference between the level of integration of climate information in the 2013-17 CIDP compared with the 2018-2022 CIDP?

8. If the CCCF has led to integrating climate information into the CIDP, what were some of the enabling factors? Was it because of any of the following?

$\square \quad$ There was a policy framework in place that strengthened requirements

$\square$ Development planners had access to tools and information

$\square$ Capacity was built to integrate climate information into the CIDP

$\square \quad$ Leadership demonstrated the need

$\square$ Coordination took place

$\square$ Finances were available to do so

$\square$ Demand/support from national, county, or sector officials

$\square \quad$ Other reasons 
9. If the CCCF did not lead to the integration of climate information into the CIDP, what were the barriers and why do you think they exist? Are there steps being taken to address them?

10. From a national perspective, how have the experiences of first mover counties that have established CCCFs, such as Makueni and Wajir, helped to raise awareness of climate-related issues and responses?

11. Do you think the CCCF has led to integrating climate information into the CIDP? Why or why not?

12. How do you think the CCCF is functioning? Are county/ward committees receiving the funds to support adaptation in villages?

\section{Main Research Question: What are the early impacts and challenges of implementing the CIDP in relation to adaptation action?}

13. Do you think the CIDP has led to climate action on the ground? Why or why not?

14. If yes, what kinds of adaptation actions are being implemented and how are they helping the climate-vulnerable? Are they being funded by the CCCF or other funds?

15. How would you describe the relationship between the national and county governments when it comes to implementing adaptation projects? Has it been an easy or challenging relationship? Why or why not?

\section{APPENDIX C: PILOTING CCCF MECHANISIMS}

Adapted from Crick et al. (2019).

\section{Phase 1: The Initial Pilot}

In 2011, the first pilot of what would later become CCCFs began in Isiolo County with the development of a program to co-generate information about the limitations of the existing planning system to build local governments' capacities to respond to climate change. This pilot aimed to integrate climate change into development planning and implement principles of devolved governance as introduced in the constitution and County Governments Bill of 2012. This devolved climate finance mechanism, called the County Adaptation Fund (CAF), was designed to enable Isiolo's county government to access climate finance. The CAF tested a decision-making process that allows local communities to control their adaptation priorities to ensure greater social inclusion and public accountability and a monitoring and evaluation (M\&E) system to track the effectiveness of local adaptation investments in climate-resilient development. The CAF pilot generated benefits for more than 18,000 people through increased access to water, pasture management, and livestock health. The capabilities of institutions at the ward level were demonstrated through this pilot project as well.

\section{Phase 2: Scaling Out}

Success of the pilot project in Isiolo prompted the scaling out of the mechanism to four more counties: Kitui, Garissa, Makueni, and Wajir. Using the wider experiences of the Ada Consortium in supporting climate adaptation, the original components of the CAF were refined to develop the four central components of the CCCF:

1. A fund to finance climate action

2. Adaptation planning committees at county and ward levels

3. Climate information and resilience planning tools

4. An M\&E system

This phase aimed to institutionalize the CCCF mechanism within county development planning and budget procedures. Key activities of this phase included incorporating climate change into CIDPs; developing legislation to formalize the establishment and functionality of the funds and county- and ward-level adaptation planning committees; developing county CIS plans; and testing resilience planning tools to ensure social inclusion and that the needs of vulnerable groups were met. The key achievements of this scaling effort included establishing five CCCFs with functional structures; completing relevant and sustainable interventions as a result of county and ward climate change planning structures; establishing five county CIS plans and associated resilience planning tools to enable prioritization of appropriate public goods investments; adopting monitoring systems that track how adaptation actions build resilience and enhance economic development; and implementing over 100 public goods investments that directly benefited more than 500,000 people and were prioritized by local communities. While the second phase brought successes, there were also challenges associated with county governments' capacities to establish themselves in conjunction with integrating CCCF mechanisms into planning systems. Nonetheless, both phases of the piloting project demonstrated a model partnership between state and nonstate actors to implement the funds and deliver local adaptation action successfully. 
Ada Consortium (Adaptation Consortium). 2015a. Climate Information Services (CIS) for Improved Livelihood and Decision-Making: A Practical Guide. CIS Case Study. Nairobi: Ada Consortium. https://www.adaconsortium.org/ index.php/component/k2/item/347-cis-case-studies-climate-informationservices-cis-for-improved-livelihood-and-decision-making-a-practicalguide.

Ada Consortium. 2015b. Climate Information Services (CIS) Intermediary Network: Lessons from Kenya. CIS Case Study. Nairobi: Ada Consortium. https://www.adaconsortium.org/index.php/component/k2/item/346climate-information-services-cis-intermediary-network-lessons-from-kenya.

Ada Consortium. 2015c. The County Climate Information Services (CIS) Plan: Developing Decentralized, User-Relevant Climate Information. CIS Case Study, Nairobi: Ada Consortium. https://www.adaconsortium.org/index.php/ component/k2/item/345-cis-case-studies-the-county-climate-informationservices-cis-plan-developing-decentralized-user-relevant-climateinformation.

Ada Consortium. 2016. Backgrounder: Building Resilience through Mainstreaming Climate Change into County Development Planning. Nairobi: Ada Consortium.

CGG (County Government of Garissa). 2013. "County Integrated Development Plan." Garissa, Kenya: CGG.

CGG. 2018. "Second Garissa County Integrated Development Plan (20182022)." Garissa, Kenya: CGG.

CGI (County Government of Isiolo). 2013. "Isiolo County Integrated Development Plan, CIDP 2013-2017," Isiolo, Kenya: CGI.

CGI. 2018. "County Integrated Development Plan 2018-2022." Isiolo, Kenya: CGI.

CGoK (County Government of Kitui). 2013، "First County Integrated Development Plan 2013-2017." Kitui, Kenya: CGoK.

CGoK. 2018، "County Integrated Development Plan 2018-2022." Kitui, Kenya: CGoK.

CGW (County Government of Wajir). 2013. "First County Integrated Development Plan 2013-2017." Wajir, Kenya: CGW.

CGW. 2017. "Programme Based Budget Report for the First Supplementary Budget FY 2017/18." Wajir, Kenya: CGW.

CGW. 2018a. "Wajir County Climate Change Fund Inventory of Adaptation Investments 2013-2016." Wajir, Kenya: CGW.
CGW. 2018b. "Wajir County Integrated Development Plan 2018-2022." Wajir, Kenya: CGW.

CGW. 2019. "Governance Plan: County Government of Wajir." Directorate of Governance and Ethics. Wajir, Kenya: CGW.

CoG (Council of Governors), 2020. "About Maarifa." Maarifa Centre. https:// maarifa.cog.go.ke/.

Crick, F., C. Hesse, V. Orindi, V. Bonaya, and J. Kiiru. 2019. Delivering Climate Finance at the Local Level to Support Adaptation: Experiences of County Climate Change Funds in Kenya. Nairobi: Ada Consortium.

Dimbore, R. 2019. "Fighting the Impact of Climate Change One Radio Show at a Time." Mercy Corps. https://www.mercycorps.org/articles/kenya/fightingimpact-climate-change-one-radio-show-time.

Dinshaw, A., N. Ginoya, P. Preethan, A. Nambi Appadurai, and M. Gutierrez. 2018. "Mainstreaming Adaptation in Action: Case Studies from Two States in India." Working Paper. Washington, DC: World Resources Institute. http:// www.wri.org/publication/ mainstreaming-adaptation-action.

Esipisu, I. 2016. "Innovative Water Storage Helps Kenyans Thrive in Drought." Reuters, July 11. https://www.reuters.com/article/us-kenya-water-innovation/ innovative-water-storage-helps-kenyans-thrive-in-drought-idUSKCNOZROF5.

GoK (Government of Kenya). 2010. "National Climate Change Response Strategy." Nairobi: GoK.

GoK. 2013. "National Climate Change Action Plan 2013-2017." Nairobi: Ministry of Environment and Mineral Resources, GoK.

GoK. 2016a. "National Adaptation Plan." Nairobi: Ministry of Environment and Forestry, GoK.

GoK. 2016b. "The Climate Change Act No. 11 of 2016." Nairobi: GoK.

GoK. 2018a. "National Climate Change Action Plan (NCCAP) 2018-2022." Nairobi: Ministry of Environment and Forestry, GoK.

GoK. 2018b. "County Integrated Development Plans (CIDPs)." Nairobi: Ministry of Devolution and ASALs, GoK. http://www.devolutionasals.go.ke/countyintegrated-development-plans/.

GoK. 2018c. "National Climate Change Adaptation Plan II 2018-2022." Nairobi: Ministry of Environment and Forestry, GoK. http://www.kcckp.go.ke/ nccap-ii-2018-2022/.

GMC (Government of Makueni County). 2013. "First County Integrated Development Plan 2013-2017." Wote, Kenya: GMC. 
GMC. 2018a. "County Budget Review and Outlook Paper - 2018." Wote, Kenya: Department of Finance and Socio-Economic Planning, GMC.

GMC. 2018b. "Makueni County Climate Change Fund Inventory Adaptation Investments 2013-2017." Wote, Kenya: GMC.

GMC. 2018c. "Makueni County Integrated Development Plan (CIDP) 20182022." Wote, Kenya: GMC.

IFRC (International Federation of Red Cross and Red Crescent Societies). 2018. "Emergency Plan of Action (EPOA) Kenya: Floods." IFRC.

IIED (International Institute for Environment and Development). 2013. Responding to Climate Change in Kenya by Strengthening Dryland Governance and Planning. London: IIED. https://www.iied.org/respondingclimate-change-kenya-strengthening-dryland-governance-planning.

KMD (Kenya Meteorology Department). 2017. "Wajir County Climate Information Services Plan." Nairobi: KMD. https://www.adaconsortium.org/ index.php/component/k2/item/364-wajir-climate-information-service-plan.

Langat, A. 2017a. "Climate Change Adaptation: Kenya Goes Local with a Bottom-Up Approach." New Humanitarian, March 3. http://www. thenewhumanitarian.org/feature/2017/03/03/climate-change-adaptationkenya-goes-local-bottom-approach.

Langat, A. 2017b. "For Women in Kenya's Dry North, Water Is Power." Reuters, June 16. https://www.reuters.com/article/us-kenya-climatechange-waterwomen-idUSKBN1971JD.

Lovell, $\mathrm{E}_{1,}$ J. Twigg, and G. Lung'ahi. 2019. Building Resilience for All: Intersectional Approaches to Reducing Vulnerability to Natural Hazards in Nepal and Kenya. London: BRACED.

MoALF (Ministry of Agriculture, Livestock, and Fisheries). 2016. "Climate Risk Profile for Makueni." Kenya County Climate Risk Profile Series. Nairobi: MoALF

MoALF. 2017. "Climate Risk Profile for Wajir County." Kenya County Climate Risk Profile Series. Nairobi: MoALF, https://cgspace.cgiar.org/rest/ bitstreams/156049/retrieve.

MoENR (Ministry of Environment and Natural Resources). 2015. "Kenya's Intended Nationally Determined Contribution (INDC)." Nairobi: MoENR. https://www4.unfccc.int/sites/ndcstaging/PublishedDocuments/Kenya\%20 First/Kenya_NDC_20150723.pdf.

MoENR. 2016. "National Climate Change Framework Policy." Nairobi: MoENR.

Mogelgaard, K, A. Dinshaw, N. Ginoya, M. Gutiérrez, P. Preethan, and J. Waslander. 2018. From Planning to Action: Mainstreaming Climate Change Adaptation into Development. Working Paper. Washington, DC: World Resources Institute. https://www.wri.org/publication/climate-planning-toaction.
Muema, E. J. Mburu, J. Coulibaly, and J. Mutune. 2018. "Determinants of Access and Utilization of Seasonal Climate Information Services among Smallholder Farmers in Makueni County, Kenya." Heliyon 4 (11): e00889.

Murphy, D., and V. Orindi. 2017. Kenya's County Climate Change Funds. Snapshot Country Brief 2b. NAP Global Network.

ND-GAIN (Notre Dame Global Adaptation Initative). 2017. ND-GAIN Country Index, https://gain-new.crc.nd.edu/ranking.

Nduku, L.M., S. Omuterema, and J.0. Gweyi. 2016. "Evaluation of the Nature of Drought Experienced in Makueni County, Kenya." Research on Humanities and Social Sciences 6 (16): 92-102

Odhiambo, M.0. 2014. The Unrelenting Persistence of Certain Narratives: An Analysis of Changing Policy Narratives about the ASALs in Kenya. IIED Country Report. London: IIED.

PRISE (Pathways to Resilience in Semi-arid Economies). 2016. "Kenya: Country Situation Assessment." Working Paper. Nairobi: PRISE.

Richard, K.T.K., N.O.C. Onyango, J.P. Mbuvi, and G. Kironchi. 2012. "Climate Change and Variability: Farmers' Perception, Experience and Adaptation Strategies in Makueni County, Kenya." Asian Journal of Agriculture and Rural Development 2 (3): 411.

Runhaar, H., B. Wilk, A. Persson, C. Uittenbroek, and C. Wamsler. 2017. "Mainstreaming Climate Adaptation: Taking Stock about 'What Works' from Empirical Research Worldwide." Regional Environmental Change 18 (4): 1201-10.

Speranza, J., F. Maschietto, L.C. Costa, and V. Elias de Oliveira. 2018. Assessment of the Limits, Challenges, and Opportunities for Adaptation Mainstreaming in Brazilian Cities, Internal document for the Ministry of Environment in Brazil (in Portuguese). Washington, DC: World Resources Institute.

UNDP (United Nations Development Programme). 2012. Climate Risks, Vulnerability and Governance in Kenya: A Review. New York: UNDP.

USAID (United States Agency for International Development). 2019. "Food Assistance Factsheet: Kenya." Washington, DC: USAID,

van Steenbergen, F., T. Alemayehu, K. Woldearegay, and M.A. Perez. 2019. Guideline: Green Roads for Water. Washington, DC: World Bank. 


\section{ACKNOWLEDGMENTS}

We are pleased to acknowledge our funder, the Federal Ministry for Economic Cooperation and Development of Germany (BMZ). BMZ has provided generous support to carry out research for this working paper. The authors would like to thank Kenya's Council of Governors for providing access to respondents and feedback on this paper. The authors would also like to thank all the respondents in this paper for their time and perspective on mainstreaming adaptation. The authors would like to thank the internal and external reviewers of this paper who have provided us important feedback to improve the paper. They are Amartya Deb, Ayesha Dinshaw, Christian Ledwell, Jack McClamrock, Kathleen Mogelgaard, Peter Ndunda, and Victor Orindi. Finally, the authors would like to thank Rebecca Carter for her guidance on this paper.

We are pleased to acknowledge our institutional strategic partners, who provide core funding to WRI: Netherlands Ministry of Foreign Affairs, Royal Danish Ministry of Foreign Affairs, and Swedish International Development Cooperation.

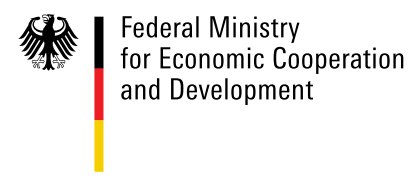

\section{ABOUTTHEAUTHORS}

Moushumi Chaudhury was an associate in the Climate Resilience Practice at WRI. She worked on mainstreaming adaptation into development and building capacity on a range of adaptation topics.

Contact: moushumi.chaudhury@gmail.com

Tonya Summerlin was an intern at WRI when conducting research for this paper. She has since graduated with an M.S. in environmental policy from the University of Michigan's School for Environment and Sustainability.

Contact: tsummer@umich.edu

Namrata Ginoya is a manager of resilience and energy access with WRI India's Energy Team. She works on mainstreaming adaptation into development with a focus on energy access.

Contact: nginoya@wri.org
ABOUT WRI

World Resources Institute is a global research organization that turns big ideas into action at the nexus of environment, economic opportunity and human well-being.

\section{Our Challenge}

Natural resources are at the foundation of economic opportunity, and human well-being. But today, we are depleting Earth's resources at rates that are not sustainable, endangering economies and people's lives. People depend on clean water, fertile land, healthy forests, and a stable climate. Livable cities and clean energy are essential for a sustainable planet. We must address these urgent, global challenges this decade.

\section{Our Vision}

We envision an equitable and prosperous planet driven by the wise management of natural resources. We aspire to create a world where the actions of government, business, and communities combine to eliminate poverty and sustain the natural environment for all people.

\section{Our Approach}

COUNT IT

We start with data. We conduct independent research and draw on the latest technology to develop new insights and recommendations. Our rigorous analysis identifies risks, unveils opportunities, and informs smart strategies. We focus our efforts on influential and emerging economies where the future of sustainability will be determined.

\section{CHANGE IT}

We use our research to influence government policies, business strategies, and civil society action. We test projects with communities, companies, and government agencies to build a strong evidence base. Then, we work with partners to deliver change on the ground that alleviates poverty and strengthens society. We hold ourselves accountable to ensure our outcomes will be bold and enduring.

\section{SCALE IT}

We don't think small. Once tested, we work with partners to adopt and expand our efforts regionally and globally. We engage with decision-makers to carry out our ideas and elevate our impact. We measure success through government and business actions that improve people's lives and sustain a healthy environment.
Maps are for illustrative purposes and do not imply the expression of any opinion on the part of WRI, concerning the legal status of any country or territory or concerning the delimitation of frontiers or boundaries.

cc) creative $\quad$ Copyright 2020 World Resources Institute. This work is licensed under the Creative Commons Attribution 4.0 International License.

cccommons (i) To view a copy of the license, visit http://creativecommons.org/licenses/by/4.0/ 